\title{
Incidencia de homicidio por arma blanca en Morgue de Lima, julio 2010 a julio 2012
}

\author{
Jessica Santillán, Rosa Carrera, Aronés Shérmany, Rafael Cano, Rosángela Vargas
}

Instituto de Medicina Legal, Ministerio Público, e Instituto de Patología, UNMSM

Introducción: Las armas blancas son instrumentos lesivos manuales, de fácil acceso, que penetran la superficie corporal por filo, punta o ambos, causando lesiones de frecuente evaluación pericial en personas y cadáveres.

Objetivos: Determinar la incidencia de lesiones por arma blanca según sexo, grupo etario, tipo de lesión, segmento afectado, causa de muerte, alcoholemia.

Diseño: Estudio descriptivo, retrospectivo, transversal.

Institución: Instituto de Medicina Legal, Ministerio Público, e Instituto de Patología, UNMSM.

Material de estudio: Informes periciales de necropsias médico legales.

Intervenciones: Análisis de protocolos de necropsias, exámenes químico-toxicológicos e información de levantamiento de cadáver.

Principales medidas de resultados: Medidas de tendencia central, frecuencias.

Resultados: De julio 2010 a julio 2012, se realizaron 9469 necropsias medicolegales; 180 se debieron a lesiones por arma blanca, edades de 07 a 72 años, edad promedio 36 años, sexo masculino 82,5\% (151), adultos 30 a 59 años 47\% (86) y adultos jóvenes 20 a 29 a 32\% (59), tipo homicida en 95\% (174), punzocortante $88 \%$ (161), degüello 8\% (15), segmentos más afectados tórax $37 \%$ (68) y cuello $25 \%$ (46); dosaje de alcohol etílico positivo en sangre $43 \%$ (79),

Conclusiones: Las heridas por arma blanca punzocortante penetrante fueron las más frecuentes, afectando segmentos corporales vitales, como tórax y cuello.

Palabras clave: Arma blanca, herida punzocortante.

\section{Perfil cineantropométrico en futbolistas peruanos de alto rendimiento y su asociación con el consumo de energía y nutrientes. Marzo 2010}

\author{
Santiago Yata, Patricia Vega, Ito Flores
}

EAP de Nutrición, Facultad de Medicina, UNMSM

Objetivos: Determinar la asociación entre el perfil cineantropométrico y el consumo de energía y nutrientes en futbolistas peruanos de alto rendimiento.

Diseño: Descriptivo, de corte transversal y ambispectivo.

Institución: EAP de Nutrición, Facultad de Medicina, UNMSM.

Participantes: Futbolistas peruanos de alto rendimiento.

Intervenciones: En marzo de 2010, en 44 futbolistas peruanos de alto rendimiento, de los clubes Alianza Lima, Universitario, San Martín de Porres y Sporting Cristal, con edades entre los 18 y 35 años, se realizó un total de 23 medidas antropométricas, siguiendo el protocolo de la Sociedad Internacional para el Avance de la Cineantropometría (ISAK). El somatotipo fue calculado con el modelo propuesto por Heath y Carter (1990) y la composición corporal con el modelo propuesto por Ross y Kerr (1993).

Principales medidas de resultados: Cantidad de energía (Kcal) y nutrientes consumidos ( $\mathrm{g}, \mathrm{mg}$ ). Porcentajes de masas muscular, adiposa y ósea, puntajes de endomorfismo, mesomorfismo y ectomorfismo. Puntaje de correlación.

Resultados: El somatotipo promedio fue mesoendomórfico $(3,0-4,8-2,1)$ y los porcentajes de masa muscular, adiposa y ósea fueron $24,2 \%, 46,7 \%$ y $12 \%$, respectivamente. El consumo de energía fue en promedio $3660 \mathrm{kcal}$, siendo la distribución porcentual de lípidos, proteinas y carbohidratos de $27 \%, 14,1 \%$ y $58,8 \%$, respectivamente. Se encontró asociación directa y estadísticamente significativa entre consumo de energía y lípidos con la masa adiposa y endomorfismo. Igualmente, el consumo de proteínas, hierro y vitamina $\mathrm{C}$ con la masa muscular y mesomorfismo.

Conclusiones: El futbolista peruano presenta valores elevados de tejido adiposo y endomorfismo, lo cual se asocia a un consumo elevado de lípidos en la dieta.

Palabras clave: Cineantropometría, somatotipo, energía, nutrientes, fútbol. 